\title{
EL MOTÍN DE LA LAGUNA DE 1909 Y SUS IMPLICACIONES POLÍTICAS
}

\author{
Said Karboune Rodríguez* \\ Universidad de La Laguna
}

\section{RESUMEN}

Este trabajo tiene como objetivo dar a conocer los graves sucesos que se vivieron en la ciudad tinerfeńa de La Laguna entre los días 27 y 28 de mayo del ańo 1909 y tratar de explicar las razones por las que los mismos ocurrieron y algunas de sus consecuencias. Los resultados nos permiten concluir que si bien los disturbios no fueron de extrema gravedad sí constituyeron un fenómeno social único y causaron un gran revuelo en la sociedad del momento. Esta investigación aspira a contribuir a dar a conocer la mentalidad de la época y también los conflictos que existían en el seno de la Iglesia católica de las Canarias occidentales**.

Palabras clave: Disturbios, Sucesos, Beyro, Moure, Iglesia católica, Paules.

THE REVOLT OF LA LAGUNA IN 1909

AND ITS POLITICAL IMPLICATIONS

\section{Abstract}

This work aims to provide some important insights about the riots that were experienced in the city of La Laguna (Tenerife) in 1909 and try to explain the reasons why it occurred and its oblivion. The results allow us to conclude that while the riots were not extremely serious, it were an unique social phenomenom and caused a controversy in the society at the time. This research looking for to help us to understand the mentality of the time and also to know the conflicts that existed inside the Catholic chuch of Western Canaries.

Keywords: Riots, disturbances, Beyro, Moure, Catholic Church, Paules. 
En ese acto heroico, patriótico, noble de los laguneros se refleja todo el cariño, todo el amor y todo el sentimiento de los isleńos para con los suyos y lo suyo; allí hay alteza, allí hay civismo ${ }^{1}$.

\section{INTRODUCCIÓN}

La historia de Canarias, como la de otros territorios insulares, ha tenido que superar la fragmentación que la geografía impone a su objeto de estudio. Ello ha llevado a una rica producción académica de trabajos de historia local, comarcal o insular, pese a lo cual hay que destacar que algunos episodios de la misma han caído en el más completo olvido. Ejemplo de ello son las jornadas de tensión social que la ciudad de La Laguna vivió entre el 27 y 28 de mayo de 1909. Un capítulo desconocido que nos habla sobre las tensiones sociales y religiosas existentes a comienzos del siglo pasado en la ciudad de los Adelantados. De igual modo, estos sucesos muestran la lucha de poder entre diferentes sectores del clero lagunero, una pugna que, como este trabajo demostrará, tuvo un reflejo en una sociedad lagunera que no solo no se mantuvo al margen, sino que tomó parte activa en ella.

\section{LOS DISTURBIOS DE LA LAGUNA EN LA HISTORIOGRAFÍA}

En mayo de 1909 las calles de la ciudad de La Laguna fueron testigos de un motín que, si bien sacudió a la sociedad del momento, hoy es completamente desconocido por los habitantes de la ciudad universitaria. Ninguna placa ni monumento recuerda lo ocurrido. Y es que si algo se puede afirmar en torno a los acontecimientos tratados en el presente artículo es que apenas han sido mencionados en la producción historiográfica de las islas. Este silencio podría llevar a pensar en una cierta intrascendencia, pero lo cierto es que la documentación hemerográfica de la época muestra todo lo contrario, tal y como vamos a exponer detalladamente en las siguientes páginas.

Así, una temprana mención a los disturbios de La Laguna se encuentra en el conocido como Libro Blanco del MPAIAC, editado en 1970 con el título de El Nacionalismo revolucionario de Canarias, la "crisis» colonial de Madrid, fase actual de nuestra lucha nacional y revolucionaria, detrás del cual estuvo el abogado independentista Antonio Cubillo Ferreira (1930-2012). En sus páginas se hace un repaso a la historia del archipiélago desde la perspectiva africanista e independentista defen-

* Graduado en Historia. Universidad de La Laguna. Tenerife (Canarias). España. correo electrónico: saidkr10@gmail.com.

** Agradezco a mis profesores Inmaculada Blasco y Manuel de Paz las sugerencias realizadas y su inestimable apoyo.

1 «Una carta» (14 de agosto de 1909). El Progreso, n. ${ }^{\circ} 1183$, p. 2. 
dida por dicho político ${ }^{2}$, siendo interesante para lo que aquí nos ocupa el siguiente fragmento en que situaba como hitos históricos tanto la concesión de los Puertos Francos en 1852, como los disturbios laguneros de 1909:

... la burguesía canaria, ante las magníficas posibilidades que se le ofrecían para desarrollar su economía y sus propios intereses, olvidaría pronto sus aspiraciones de independencia y traicionaría al pueblo canario en su lucha por la liberación. $\mathrm{Y}$ en efecto, durante algunos decenios así fue, pero bien pronto, las propias capas burguesas que habían abandonado el combate por la Independencia en 1852, se comienzan a dar cuenta que las libertades acordadas eran insuficientes, debido a las estructuras coloniales administrativas establecidas en el Archipiélago [...]. Hacia finales de siglo, y con motivo de las guerras de Cuba y Filipinas, España temió por Canarias y reforzó todas las guarniciones con tropas venidas de la metrópoli, pero el malestar popular era bastante grande y cada día se manifestaba por diversos medios. Hacia 1909 la situación se vuelve incluso peligrosa ya que se comienza a hablar de Independencia como en Cuba y Filipinas y es precisamente en la ciudad de La Laguna donde se verifican una serie de manifestaciones populares de este tipo llegando incluso a ondear en el Ateneo, la bandera de la Independencia con siete estrellas verdes. Ante tal situación, el gobierno de Madrid, que acababa de perder Cuba, Filipinas, Puerto Rico no quiso adoptar la vía violenta sino la de la negociación y como además sabía, que el movimiento estaba dirigido en parte por la burguesía nacional (la cual siempre prefiere discutir que luchar) pues llegó a un acuerdo por el cual se daba una cierta Autonomía a los Cabildos Insulares, autonomía que pareció conformar a la burguesía canaria de principios de siglo 3 .

Como puede comprobarse, el documento del MPAIAC aseguraba que en 1909 se habían producido manifestaciones populares en las calles de La Laguna en defensa de la independencia de Canarias. Y ello sin aportar ninguna fuente ni referencia que avale tales afirmaciones. Esto no es sorprendente si se tiene en cuenta que se trata de un documento propagandístico y no de un trabajo académico. Pero este no es el único documento que menciona los disturbios laguneros atribuyendo a los mismos un carácter independentista. Otro ejemplo de ello lo encontramos en la revista Negaciones, en cuyas páginas se publicó un artículo titulado «El hecho colonial canario» que aseguraba lo siguiente:

En el año 1909, como consecuencia de la suspensión por la jerarquía eclesiástica de dos religiosos conocidos por sus ideas separatistas, el pueblo de La Laguna se

2 Garí Hayek, D. (1995). Antonio Cubillo Ferreira, Las Palmas de Gran Canaria y Santa Cruz de Tenerife: Editorial Benchomo.

3 El Nacionalismo revolucionario de Canarias, la «crisis» colonial de Madrid, fase actual de nuestra lucha nacional y revolucionaria. Departamento de información y formación política del MPAIAC, 1970, 76 pp. En Lurra (1978). Canarias otro Volcán. San Sebastián: Lur y Hordago, p. 153. 
subleva, controlando la ciudad durante tres días, en los que la bandera de la independencia con las siete estrellas verdes llegó a ondear en el Ateneo ${ }^{4}$.

Con esto ya se nos ofrece más información al referirse a los supuestos motivos de los disturbios, protagonistas e incluso a la duración de los mismos. Pero sin duda, la obra en la que más detalladamente queda descrito lo sucedido es el libro Afrika Guanche, de José Diego Díaz-Llanos Guigou, donde puede leerse el siguiente relato:

1909.- En el sermón que pronunciara en la Iglesia Matriz de Nuestra Señora de la Concepción de AnAza [sic], aquél gran orador, patricio e insigne cura patriota, Dr. D. Santiago Beyro Martín, con motivo del aniversario de aquel nefasto 3 de mayo de 1494, fue tanta la elocuencia al cantar las glorias patrias guanches, tanto su sentimiento, tanta su emoción y tan pulcro en el decir dentro de un fondo netamente cristiano, que al terminar la oración sagrada el Ayuntamiento de la capital en Corporación, pasó a felicitarle [...]. Como la gota que rebosó el vaso de agua, fue para el Provisor y Vicario de la Diócesis Nivariense, D. Manuel Sansó y Garrabón, el sermón de D. Santiago que acabamos de relatar, por lo que sin pensárselo dos veces, decreta la «suspensión de misa» de este cura y del otro cura patriota, D. José Rodriguez Moure. La reacción del pueblo al ver como castigaban a estos sacerdotes por relatar la verdad histórica no se hizo esperar.

En Aguere se amotina la población, saliendo a la calle una impresionante manifestación encabezada por el alcalde, D. Juan Ascanio y Nieves, y por aquel otro gran patriota que era en ese momento Presidente de aquel Ateneo, nuestro inolvidable y marginado D. Benito Pérez Armas, con apedreamiento al Palacio Episcopal y a la Residencia de los Padres Paúles - hoy Asilo de Ancianos-, degenerando aquello en un verdero motín, por lo que no le quedó más remedio que salir de madrugada y precipitadamente desde el Hotel Aguere donde se hospedaba, el Vicario Dr. Samsó, quien llegó al puerto de Anaza por un camino de segundo orden, embarcándose para GuiniguAda y nunca más regresando a CHINET, restituyendo en sus puestos a nuestros africanos curas, el Obispo de la Diócesis, D. Nicolás Rey Redondo. Para sofocar aquella rebelión callejera, intervino el ejército 5 .

Sin embargo, al igual que en los anteriores ejemplos, su autor no cita ninguna de las fuentes de las que ha obtenido los datos. Pese a ello, hay que destacar que Díaz-Llanos Guigou aporta los nombres de los protagonistas de aquella olvidada jornada, así como las consecuencias de la misma. La información que aporta, de gran valor, ha servido para comenzar a rastrear los sucesos en la prensa de la época y, de esta manera, elaborar el presente trabajo de investigación. Así, continuando con el rastreo bibliográfico, encontramos una tardía mención hecha por el historiador

${ }^{4}$ Cabellos, Ventura (1977). «El hecho colonial canario». Negaciones, revista critica de teoría, historia y economía, núm. 4, p. 164.

5 Díaz-Llanos Guigou, J.D. (1986): Árika Guanche, Santa Cruz de Tenerife: Autor Editor, Heliodoro Rodríguez López, pp. 167-168. 
Gregorio Cabrera Déniz, quien en un trabajo sobre la Iglesia lagunera aparecido en el marco del IX Coloquio de Historia Canario-Americana, comenta:

Los conflictos que continuamente protagoniza el clero de La Laguna, bajo el mandato de D. Nicolás Rey Redondo, se reproducen ya entrado el siglo xx, siendo quizás el más espectador el que enfrentó a los dos sacerdotes citados, en mayo de 1909, con el entonces Provisor y Vicario de la Diócesis, D. Manuel Samsó y Garrabón. Los acontecimientos llevaron incluso a una manifestación de apoyo a D. José Rodríguez Moure y Santiago Beyro, que encabezada por el Alcalde, D. Juan de Ascanio y Nieves, y el Presidente del Ateneo, D. Benito Pérez Armas, exigieron del Obispo su intervención. La actitud popular obligaría al Provisor a abandonar la diócesis nivariense y marcó el momento más sombrío del largo episcopado... ${ }^{6}$.

Así pues, estamos hablando de un acontecimiento que se nos presenta, según la fuente que leamos, bien como un conflicto eclesiástico, bien como un motín independentista. Lo contradictorio entre ambas versiones ha motivado el interés por indagar sobre lo ocurrido y tratar de esclarecer, en la medida de lo posible, las causas de estas manifestaciones populares. De igual modo, la nula presencia de estos sucesos en los manuales de Historia de Canarias plantea un interrogante sobre el alcance de los mismos. ¿¿Fue realmente un motín?, ¿¿la población se implicó? Y en ese caso, ¿las élites laguneras o las clases populares?, ¿realmente hubo manifestaciones de separatismo en la protesta? Responder a estas preguntas es lo que se busca en las siguientes páginas.

\section{LOS SUCESOS DE LA LAGUNA: UN MOTÍN URBANO}

En primer lugar, veamos cómo se iniciaron los sucesos de acuerdo a la prensa de la época, la cual cubrió ampliamente los acontecimientos desencadenados la tarde del día 27 de mayo de 1909. El origen de los sucesos estuvo en el momento que comenzó a circular la noticia de la suspensión de misa contra los sacerdotes Santiago Beyro y José Rodríguez Moure. Una novedad que, al parecer, corrió como la pólvora por la ciudad de los Adelantados, cuya población tomó las calles en defensa de los citados clérigos.

Así, la prensa comenta como a las «ocho de la noche se dispararon infinidad de cohetes voladores, reuniéndose numeroso gentío en la plaza de la Catedral, en la que en breves momentos se congregó el pueblo en masa». Sobre la composición social de los congregados, los medios destacan la participación de personas de «todas las clases sociales, viéndose también centenares de mujeres que protestaban de lo ocu-

${ }^{6}$ Cabrera Déniz, G.J. (1990). «La Laguna: Iglesia y opinión en el último cuarto del siglo XIX». Coloquio de Historia canario-americana, IX, pp. 345-365. 
rrido á los distinguidos paisanos» ${ }^{7}$. Esta información nos habla del interclasismo de la protesta, así como del importante papel jugado por las mujeres. Respecto a esto último, conviene no olvidar que, en esta época, a inicios del siglo xx, la Iglesia católica experimentó un auténtico proceso de feminización, con una cada vez mayor presencia y movilización de mujeres en sus templos y actividades de caridad y beneficencia ${ }^{8}$. Sin duda, esas mujeres debieron ser feligresas de los sacerdotes agraviados.

La concentración, encabezada por el alcalde de la ciudad, Juan de Ascanio y Nieves (1849-1924) y el presidente del Ateneo de La Laguna, Benito Pérez Armas (1871-1937) ${ }^{9}$, se dirigió al Palacio episcopal, donde el alcalde, que había sido designado por los manifestantes con la «misión de hacer saber al Prelado los deseos del pueblo en tan enojoso asunto" fue recibido por el entonces obispo de la diócesis nivariense, Nicolás Rey y Redondo (1834-1917) ${ }^{10}$. La respuesta del obispo fue asegurar que «no tenía conocimiento de la suspensión de los oficios de misa, confesión, etc., acordada contra los señores sacerdotes de referencia, pero que él procuraría arreglar hoy el asunto.» Una postura que encolerizó a la multitud, la cual reaccionó apedreando el palacio episcopal de una manera tan violenta que «no quedó sano ni un solo cristal ${ }^{11}$.

Según el periódico El Progreso, tras esta acción «los manifestantes dirigiéronse á la plaza de Santo Domingo, donde tienen su domicilio los Paules», frailes mayoritariamente peninsulares, que controlaban el Seminario, entonces ubicado en dicho ex convento de Santo Domingo. Allí los destrozos en el inmueble fueron de consideración y los frailes tuvieron que esconderse para, literalmente, salvar la vida. Una escena que quedó inmortalizada en una caricatura aparecida en el semanario satírico Barreno y Fuego ${ }^{12}$.

Finalmente, los manifestantes se dirigieron hacia el Hotel Aguere, en el que se hospedaba el Provisor Manuel Sansó, sacerdote catalán ${ }^{13}$ responsable de la suspensión de los dos sacerdotes isleños. Agolpado a las puertas del establecimiento, «el pueblo, pedía su destitución y la del obispo», no cediendo hasta que finalmente lograron arrancarle la anulación de todas las medidas dispuestas contra Santiago Beyro y Rodríguez Moure. Tras dicha decisión, la multitud se disolvió pacíficamente, de manera que para cuando el gobernador, Santos y Ecay, llegó a la ciudad procedente de Santa Cruz, la paz reinaba en sus calles. Fue gracias a esto que se evitó la

7 «Los sucesos de La Laguna - Obispo y frailes apedreados» (28 de mayo de 1909). El Progreso, n. ${ }^{\circ} 1118$, p. 1.

${ }^{8}$ Crespo Jiménez, L. (2008). Trato, diversión y rezo. Sociabilidad y ocio en Toledo (18871914). Cuenca: Universidad de Castilla-La Mancha, p. 122.

9 Cabrera Déniz, G.J. (2004). Benito Pérez Armas: 1871-1937. Santa Cruz de Tenerife: Parlamento de Canarias - Fundación Canaria Víctor Zurita.

10 «Los sucesos de La Laguna - Obispo y frailes apedreados» (28 de mayo de 1909). El Progreso, n. ${ }^{\circ} 1118$, p. 1.

${ }^{11}$ Idem.

12 «Episodios Laguneros» (5 de junio de 1909). Barreno y... ¡Fuego! órgano de la juventud radical, n. ${ }^{\circ} 48$, p. 1 .

13 “¿Es el mismo?» (8 de enero de 1913). El Progreso, n. ${ }^{\circ} 2221$, p. 2. 
intervención de las fuerzas del orden a las que se había ordenado acudir a La Laguna mediante un tranvía especial. Cabe preguntarse qué hubiese ocurrido si realmente la Guardia Civil hubiese intervenido con la manifestación aún en las calles. No hay que olvidar sucesos como la matanza de Oseira (ocurrida el 22 de abril de 1909), localidad gallega en la que existía una fuerte tensión entre los vecinos y el obispado, donde la intervención de la Guardia Civil terminó en tragedia: murieron siete personas, entre ellas una mujer embarazada y una niña ${ }^{14}$.

En cuanto al ambiente que se vivió en el transcurso de la protesta, el periódico La Opinión aporta datos más que interesantes sobre las quejas de la multitud. Así, es de destacar que algunos manifestantes denunciaban que lo ocurrido a los sacerdotes isleños era "como en las colonias»" ${ }^{15}$. De igual modo, detalla el contingente de fuerzas del orden movilizadas para sofocar el motín. Concretamente, asegura que en «un furgón de carga del tranvía subió un regular contingente de guardias de orden público. También en otros coches del tranvía fueron algunas parejas de la Guardia civil $\aleph^{16}$. Estos datos muestran que el gobernador había decidido aplacar la protesta mediante el uso de la fuerza, algo que no ocurrió gracias a la anulación del castigo a los sacerdotes y la consecuente disolución de la protesta. ¿Qué alcance hubiesen tenido estos acontecimientos si finalmente se hubiese producido la intervención de las fuerzas de seguridad?

Pero la tensión se mantendría durante las siguientes jornadas. Así sabemos que, pasados dos días, en La Laguna «continúa la excitación contra los padres Paules, á los que se considera como principales culpables de los graves sucesos ocurridos anteanoche en aquella ciudad», añadiendo que se esperaba que «se reanudara la protesta del pueblo contra la temible invasión frailuna que trata de apoderarse de todos los destinos de la Diócesis» ${ }^{17}$. Algo que, como veremos, se reproduciría en diversas localidades de la isla.

Asimismo, es de especial interés otra información que los medios aportan sobre la mencionada participación de las mujeres en la protesta: «Cuéntase que en los momentos más álgidos dé la manifestación, las mujeres del pueblo acarreaban las piedras, llevandolas en grandes cestas y repartiendo después los proyectiles entre los enardecidos manifestantes.» $Y$ es que según relata, las laguneras habían sido claves, pues «el acopio de la improvisada metralla hacíanlo las mujeres en los escombros que se hallan frente á la fábrica del señor Díaz Llanos, en la plaza de Santo Domingo y en la calle de Herradores, donde ahora se está reparando el pavimento»" ${ }^{18}$. Al respecto, cabe señalar que la participación de las mujeres en motines urbanos fue muy

14 Cabo, M. y Rodríguez Lago, J.R. (2019). "Matar un ruiseñor. Oseira 1909, análisis de una masacre». Cuadernos de Historia Contemporánea, vol. 41, pp. 233-253.

15 «Los sucesos de La Laguna» (29 de mayo de 1909). La Opinión, n. ${ }^{5027, \text { p. } 1 .}$

16 Idem.

17 «Después de la catástrofe-Los sucesos de La Laguna» (29 de mayo de 1909). El Progreso, n. ${ }^{\circ} 1119$, p. 2.

18 Idem. 
importante en diversas ciudades españolas entre los siglos XIX y XX, fenómeno con el que puede ser vinculado lo ocurrido en La Laguna ${ }^{19}$.

Por otra parte, haciéndose eco de la hostilidad existente hacia los mencionados paúles, la prensa advertía a las autoridades de probables «alteraciones de orden público, cosa que no tendría nada de particular por la excitación que se nota en el pueblo contra los religiosos que han venido á este país á ejercer procedimientos coloniales» ${ }^{20}$. Es decir, la percepción que se tenía era la de que los PP. Paúles habían adoptado en Canarias una actitud colonialista, fruto de la cual se habían ganado la animadversión de muchos católicos laguneros. En este sentido cabe imaginar ciertas conexiones con las incipientes expresiones de anticentralismo articuladas en torno al movimiento regionalista, unas conexiones que se pondrán de manifiesto en este trabajo de investigación.

Además, la prensa se mostró unánime respecto a los antecedentes a los que apuntaba como causas de los disturbios: la enconada enemistad existente entre paúles, de origen foráneo y clero isleño. Los periódicos afirmaban que lo ocurrido respondió a «una venganza frailuna [...] nacida del despecho y del odio más reconcentrado á los hijos del país, por parte de la Camarilla episcopal que desde hace algún tiempo viene rigiendo los destinos de la Diócesis.» Asimismo, se aseguraba que dichos elementos «dirigidos por el soberbio é iracundo Provisor de la Diócesis, venían haciendo blanco de sus odios y persecuciones á los dos citados sacerdotes canarios» ${ }^{21}$. Es decir, el choque fue presentado como el resultado de la política anti-canaria de los sacerdotes foráneos. De igual modo, se aseguró que el pretexto empleado por dicha "camarilla exótica, formada por Paules y canónigos forasteros»" fue la publicación en el periódico católico El Tiempo del artículo "La mesa del zapatero», cuyo autor era el antiguo Deán de Las Palmas, José López Martín ${ }^{23}$. Un escrito que había sido originalmente publicado en 1899 y que lanzaba una dura crítica contra las personas mezquinas, envidiosas y calumniadoras ${ }^{24}$. El que dicho periódico lo volviese a publicar ańadiéndole comentarios en defensa de Beyro, si bien sin nombrarle, actuó como detonante de su suspensión y de los sucesos posteriores.

El hecho de que el castigo fuera dictado por el Provisor Sansó motivó que la prensa le señalase en los días siguientes como responsable de lo acontecido. Así, el periódico El Progreso afirmaba, sobre el citado provisor, que «apenas llegado a La Laguna eclipsó y anuló con su montaraz intransigencia la fama que antes había adquirido el revoltoso Chaveta [...] enemigo declarado de la bandera regionalista

19 Radcliff, Pamela (1993). Elite Women Workers and Collective Action: The Cigarette Makers of Gijón, 1890-1930, Journal of Social History, n. ${ }^{\circ} 1$ (volume 27), pp. 85-108.

20 "A las autoridades» (29 de mayo de 1909). El Progreso, n. ${ }^{\circ} 1119$, p. 2.

21 «Los sucesos de La Laguna-Obispo y frailes apedreados» (28 de mayo de 1909). El Progreso, n. $^{\circ} 1118$, p. 1.

${ }^{22}$ Idem.

${ }^{23}$ López Martín, J. (24 de mayo de 1909). «La mesa del zapatero». El Tiempo, n. ${ }^{\circ} 1864$, p. 1.

${ }^{24}$ López Martín, J. (10 de abril de 1899). "La mesa del zapatero». Diario de Tenerife, n. ${ }^{\circ} 8711$, p. 3 . 
del Ateneo, a cuyo Centro tildó de filibustero en un artículo furibundo» ${ }^{25}$. Esta información permite profundizar en las causas del conflicto. En ella se apunta a otro sacerdote peninsular, que respondía al pseudónimo de Chaveta, así como a su enfrentamiento con el movimiento regionalista agrupado en torno a los jóvenes del Ateneo de La Laguna. La prensa del momento nos revela que quien se escondía tras dicha firma era ni más ni menos que Luis Palahi, que llegó a llamar "centro separatista al Ateneo de la Laguna; todo eso encubierto bajo el pseudónimo de Chaveta ${ }^{26}$.

\section{IMPACTO MEDIÁTICO Y SOCIAL DE LOS SUCESOS DE LA LAGUNA}

Como se ha mencionado, la prensa isleña analizó ampliamente los sucesos durante los días posteriores a los mismos. Por su implicación directa como medio que publicó el artículo que dio lugar al castigo contra los sacerdotes Santiago Beyro y Rodríguez Moure, el diario El Tiempo no dudó en expresar públicamente su posicionamiento. Así, en su edición del día 28 de mayo aseguraba que los antecedentes de estos sucesos debían buscarse en la lucha «de los paules contra el clero isleño y particularmente contra los ilustrados y queridos sacerdotes Sres. Beyro y Rodríguez Moure que simbolizan el espíritu canario y regional frente á la irrupción no por lenta menos sensible de elementos que en buena hora llegaran si vinieran en son de paz y evangelización $\aleph^{27}$.

Tal y como puede apreciarse, los dos bandos enfrentados estaban bien identificados y la prensa los diferenciaba de una manera bastante clara. A continuación, el citado medio reconocía que la publicación en sus páginas del artículo de López Martín había provocado que el obispo, "creyendo que ese artículo se había dado á nueva luz por excitaciones de los Sres. Beyro y Rodríguez Moure, les suspendió ayer de todas las licencias, de misa...». El periódico carga responsabilidades sobre el alcalde, afirmando que «la turba popular cometió sensibles desmanes, que dada la excitación de los ánimos debió preveer", añadiendo que es de lamentar que el "Obispo se preste tan dócilmente á imposiciones que no consideramos justificadas y protestar enérgicamonte de la suspensión de licencias que se ha dictado contra los Sres. Beiro [sic] y Rodríguez Moure á los cuales, como ciudadanos y como católicos, tenemos en el más elevado concepto» ${ }^{28}$.

El Tiempo justifica su protesta contra la decisión de Sansó asegurando que el artículo publicado en sus páginas les fue suministrado por una persona que, si

25 «Los sucesos de La Laguna - Obispo y frailes apedreados» (28 de mayo de 1909). El Progreso, n. ${ }^{\circ} 1118$, p. 1.

26 «El canónigo banqueteado» (4 de marzo de 1909). El Progreso, n. ${ }^{\circ} 1050$, p. 1.

27 «Disturbios en La Laguna-contra el prelado» (28 de mayo de 1909). El Tiempo, n. ${ }^{\circ} 1868$, p. 1.

28 «Disturbios en La Laguna-contra el prelado» (28 de mayo de 1909). El Tiempo, n. ${ }^{\circ} 1868$, p. 1. 
bien era un «admirador» de Santiago Beyro y Rodríguez Moure, «no tiene con ellos relación ninguna». Por último, protestaba "con igual energía, contra los actos reprobables que los grupos exaltados cometieron anoche en la Laguna y que si algo consiguen es perjudicar á los mismos que los realizaron, al pueblo en que tuvieron lugar, a la protesta misma que los inspiró y a la autoridad municipal que no supo preverlos», concluyendo con un llamamiento a restablecer en «sus derechos á los señores Beyro y Rodríguez Moure» ${ }^{29}$.

El mismo medio, en su edición del día 29 de mayo, vuelve a comentar lo ocurrido para asegurar que «los disturbios de la noche anterior, contraproducentes para los mismos fines de la protesta, y más que contraproducentes impropios de un pueblo culto y morigerado, dieron lugar á la saludable reacción ${ }^{30}$ que se observaba al día siguiente, con la vuelta a la calma. Pero a pesar de ello, el periódico santacrucero consideraba que el conflicto "continúa planteado en los mismos términos. Los enconos no han desaparecido con lá marcha del Sr. Sansó, antes bien se han enardecido...", es decir, estamos ante un enfrentamiento que, de seguro, venía de tiempo atrás.

Por su parte, el periódico conservador La Opinión calificó como "gravísimo" lo ocurrido en La Laguna la noche anterior, asegurando que:

Hace tiempo que una desmedida invasión de gentes extrañas -extrañas por lo peligrosas y absorventes- tiene perturbado el natural bondadoso de nuestro temperamento, llevando al sagrado de la religión sus egoísmos y sus ambiciones. [...] El clero insular, ante esa invasión, denota un lógico malestar... ${ }^{31}$.

Queda patente que existía cierto malestar entre el clero isleño a causa de la llegada de los padres paúles, la cual es equiparada a una «invasión». Por lo tanto, estamos ante un conflicto interno en la Diócesis tinerfeña, que parece haber sido provocado por la lucha de poder existente entre sacerdotes canarios y peninsulares, tal y como será mencionado. Siendo un episodio más del mismo enfrentamiento el que dio lugar a los disturbios laguneros.

En cuanto al diario autonomista El Progreso, sus comentarios sobre lo que describe como «tremenda e inesperada hecatombe» son de un especial interés, porque trataban de explicar las razones que habían llevado a la movilización popular:

La Laguna, como las demás poblaciones canarias, alientan en su espíritu un amor grande, intenso, fiel como ninguno por la honrada patria española, y ese sentimiento noble que siempre, en todas ocasiones, han demostrado los canarios, quieren desmentirlo algunos imbéciles indignos de vivir entre nosotros, que han llegado hasta suponer en los hombres más ilustres del país tibieza de amor patrio. La ofensiva sospecha se ha convertido a veces en demostraciones de hostilidad a nuestros pai-

\footnotetext{
29 Idem.

30 «Lo de La Laguna» (29 de mayo de 1909). El Tiempo, n. ${ }^{\circ} 1869$, p. 1.

31 «En La Laguna - Graves sucesos» (28 de mayo de 1909). La Opinión, n. ${ }^{\circ}$ 5026, p. 1.
} 
sanos, y esto es lo que han hecho esos frailes de La Laguna que formaban la hoy deshecha Camarilla episcopal [...]. Bien saben esos elementos que toda esa cantinela del desafecto patriótico y del peligro regionalista, es una infame suspicacia de la que algunos quieren hacer dardo venenoso para zaherir á los hijos del país, y luego lanzarlos por artes tan reprobabas como las del Padre Sansó, de los puestos que honradamente vienen desempeñando. Eso ha ocurrido en La Laguna y eso ocurrirá en otras poblaciones, si el colonial procedimiento no se evita á su debido tiempo ${ }^{32}$.

Es obvio que las motivaciones que este periódico otorga a los sucesos son de una evidente naturaleza política, denunciando la posición hostil del clero peninsular hacia los sacerdotes canarios. Pero también hacia el incipiente movimiento regionalista. La afinidad que mantenían tanto Rodríguez Moure como Beyro con dicho regionalismo les había convertido, al parecer, en objeto de acusaciones de falta de patriotismo español. Una acusación que al mismo tiempo iba acompañada de un cuestionamiento de la lealtad de los isleños.

El citado diario concluye su análisis de los sucesos de La Laguna expresando la esperanza de que "sirva de ejemplo y escarmiento lo ocurrido, y no olviden el hecho las demás autoridades, funcionarios, clérigos, monjas, frailes y particulares que nos hayan tomado por una segunda colonia filipina» ${ }^{33}$.

Es decir, de nuevo se denuncian comportamientos calificados como colonialistas, en este caso, por parte del clero peninsular. Una acusación en consonancia con el debate político del momento, en que la prensa afín al movimiento regionalista solía denunciar el trato "colonial» y la situación de olvido que padecía el archipiélago canario ${ }^{34}$. No se debe olvidar que estos sucesos tuvieron lugar apenas pasada una década del Desastre del 98 y que la pérdida de las últimas colonias, Filipinas incluida, estaba aún presente en la memoria colectiva. Por otra parte, y en relación a otro escándalo en que estaba implicado el clero, se comenta lo siguiente:

[...] ni la santidad nunca desmentida del Obispo, ni la caridad cristiana, que de ejemplo debiera servir á muchos, del fracasado Palahi, han tenido una reprimenda ni una advertencia para el joven cazador de almas y corazones, entretenidos como estaban en sermonear á un sacerdote por que en el pulpito habló de regionalismo, mientras un padrito agazapado en la sombra de una capilla, actuaba como espía de instintos rencorosos... ${ }^{35}$.

Aquí vemos una nueva referencia al sermón pronunciado por Santiago Beyro en la Concepción de Santa Cruz, asunto en que se profundizará en el siguiente apartado. Baste decir por ahora que, en contra de lo que podría sospecharse, el orador expresó en el mismo su declarado amor por España.

32 «Comentarios» (28 de mayo de 1909). El Progreso, n. ${ }^{\circ} 1118$, p. 2.

${ }^{33}$ Idem.

34 Karboune Rodríguez, Said (2019). La construcción del movimiento regionalista en Canarias: 1898-1910. Trabajo final de frado. Grado en Historia, Universidad de La Laguna [inédito].

35 «Desde La Laguna -jOh, los barbianes!» (28 de mayo de 1909). El Progreso, n. ${ }^{\circ} 1118$, p. 2. 
Asimismo, de igual interés es lo comentado en el diario liberal El País, en cuya portada se publicó un artículo que apuntaba directamente a motivaciones políticas como trasfondo de lo acontecido en las calles de La Laguna:

Nosotros, en el fondo de ése asunto, alcanzamos a ver, más que otra cosa, una cuestión política, es decir, la repercución de los idéales que se agitan en la Península, ó sea la pugna entre el centralismo y el regionalismo. No somos centralistas, ni regionalistas, sino únicamente espańoles y canarios, y por lo tanto creemos que ambos ideales, llevados hasta la intransigencia, son extramadamente perjudiciales. El regionalismo, como aquí lo quisieran algunos, ni puede ser ni tiene razón de ser dado el régimen de amplitud, de cosmopolitanismo á que se van inclinando los pueblos, y ese centralismo tiránico y absorvente [...] nos es completamente aborrecible. [...] Nosotros, para bien de Canarias y bien de España, buscamos un término medio entre ambas exageradas aspiraciones, como medio de armonizar los intereses y conveniencias de la provincia con la metrópoli. [...] Nosotros consideramos al sacerdote como un poeta, un poeta místico que recibe la inspiración de lo alto, y ciertamente, llámese este sacerdote como se llame, sea canario o sea peninsular, nos parece tan extraño verle descender a los asuntos políticos, como nos parecería extraño un político de profesión que se inspirase en las cosas del cielo ${ }^{36}$.

En estas palabras en las que se parece adoptar una postura equidistante entre las ideas centralistas y regionalistas, resulta llamativo que se refieran a la Península como "la metrópoli», término tradicionalmente empleado para hacer referencia a una nación respecto de sus colonias. Sin embargo, no muestran la misma neutralidad hacia el clero, pues critican abiertamente a los sacerdotes que se inmiscuyen en asuntos políticos, recordando que ya pasaron los tiempos en que la Iglesia «lo dominaba todo, en que los papas eran virreyes del cielo y reyes de la tierra». Adopta, por lo tanto, un posicionamiento laicista frente a un conflicto que entienden se ha desencadenado precisamente por la implicación de algunos sacerdotes en las luchas políticas del momento, protagonizadas por regionalistas y centralistas.

También de interés es lo que comenta el periódico dirigido por Patricio Estévanez $^{37}$, Diario de Tenerife, que aseguraba que «el bondadoso y querido Dr. Beyro, el sacerdote ejemplar, el ferviente patriota, ha venido sufriendo las iras de una parte del clero, aquella precisamente más allegada á Palacio y que no es del país,» en alusión a los mencionados padres paúles, «a quienes se les acusa de ser los promovedores ó instigadores de la guerra á los sacerdotes hijos del país» ${ }^{38}$. Y ya refiriéndose a la marcha de Sansó añadía:

${ }^{36}$ Molina, E. (29 de mayo de 1909). «Lo ocurrido en La Laguna». El País, n. ${ }^{\circ} 311$, p. 1.

37 Sánchez Morales, J. (2006). Patricio Estévanez. Estudio biográfico. Santa Cruz de Tenerife: Ediciones Idea; Colección: Periodistas de Canarias.

38 "Gravísimos sucesos en La Laguna» (28 de mayo de 1909). Diario de Tenerife, n. ${ }^{\circ} 6765$, p. 2. 
Nos dicen también que un señor Canónigo, acusado hace tiempo por la opinión pública de ser quién con más encono se ha mostrado hostil al Dr. Beyro, ha tenido que marcharse de la Laguna y hasta que se ha embarcado hoy mismo para la Península. Seria una medida de prudencia muy laudable. Otros debieran imitarla ${ }^{39}$.

De nuevo, queda patente el conflicto existente entre el clero que no es del país y los sacerdotes hijos del país, el cual enfrentaba en el seno de la Iglesia a isleños con los llegados desde la Península. Un enfrentamiento que dividía a la Diócesis y que además conectaba con las batallas políticas del momento, tal y como se comenta. Precisamente, de la marcha de Sansó llegaron a hacerse eco medios peninsulares, como El Diluvio de Barcelona, en cuyas páginas se comentaba al respecto: «El P. Sansó, salió de incógnito de la Laguna; no se sabe si se ha dirigido á la Península en busca de una escuadra que bombardee á las Canarias ó á Roma en busca de una excomunión para todos los isleños» ${ }^{40}$.

Sin duda, una exageración, con la que querían destacar el conflicto que separaba al mencionado clérigo del conjunto de la sociedad canaria del momento. Conflicto que, de momento, ya le costó el cargo al provisor y que, como veremos, afectó a otros sacerdotes en distintos puntos de la geografía insular. Es este el momento en que la prensa más radical no ocultará su alegría por la marcha de sacerdotes, con afirmaciones del calibre de las siguientes: «Los frailucos forasteros que arribaron á esta peña como si se tratara de la Nubia ó Cafrería, se han llevado un mico si pensaron en conquistarnos, pues, según dicen, los bobos han emigrado con rumbo á Venezuela $»^{41}$.

Pero, visto que el escándalo llegó incluso a medios barceloneses, cabe preguntarse cuál fue el impacto mediático de los disturbios en la prensa peninsular. Para esclarecerlo, citaremos algunos ejemplos. Así, a colación de lo acontecido en Tenerife, el periódico conservador La Correspondencia de España, publicó un interesante reportaje sobre los sucesos, en el cual se destacaba el rol jugado por los padres Beyro y Rodríguez Moure en el movimiento regionalista canario:

Hace algún tiempo, la comunidad de los padres Paules, formada en su totalidad por sacerdotes peninsulares, se estableció en La Laguna, y bien pronto se hizo cargo del Seminario y de otros centros docentes, ocupando algunos paules plazas en las parroquias y en la Catedral y encargándose de la mayoría de los ejercicios piadosos que en la diócesis se celebran. Esto, al decir de los bien informados, había producido alguna inquietud entre los sacerdotes del país, pues muchos se encuentran sin cargos eclesiásticos ${ }^{42}$.

\footnotetext{
${ }^{39}$ Idem.

${ }^{40}$ Fray Gerundio (17 de junio de 1909). «Notable artículo de "El Diluvio" de Barcelona». El Progreso, n. ${ }^{\circ} 1134$, p. 1.

41 «Entre pitos y flautas» (5 de junio de 1909). Barreno y... jFuego!, n. ${ }^{\circ} 48$, p. 3.

42 "Graves desórdenes en Tenerife» (29 de mayo de 1909). La Correspondencia de España, n. ${ }^{\circ} 18.735$, p. 3 .
} 
Hasta aquí parece reproducir los mismos precedentes que la prensa isleña, pero, a continuación, dedican varios párrafos a comentar el vínculo existente entre el entonces en boga movimiento político regionalista y los citados sacerdotes:

El doctor D. Santiago Beyro y Martín tiene reputación de ser el más elocuente orador sagrado de Tenerife, como lo demuestra el hecho de que en todas las solemnidades es el encargado de pronunciarla oración religiosa. Últimamente, con motivo de la Asamblea regionalista, puso de relieve su gran amor á las tradiciones canarias, y ello fué motivo para que el pueblo, sin distinción de clases ni ideas políticas, le tributará un homenaje, pidiendo a los poderes públicos que le otorgaran una alta distinción, á lo que se opuso el Sr. Beyro, que es hombre modestísimo y al que se cita siempre como ejemplo de altas virtudes.

El otro sacerdote, D. José Rodríguez Moure, maestro de ceremonias de la catedral, es hombre de talento extraordinario, de cultura vastísima y está considerado como un gran filólogo y como uno de los primeros historiadores de Canarias. Ha influido de manera poderosa en las orientaciones políticas del país, y también se distingue por el acendrado amor á las tradiciones canarias. Estas tendencias de los dos sacerdotes han servido para que muchos digan que ambos son poderosas palancas del regionalismo canario ${ }^{43}$.

Se destacaba la militancia regionalista de ambos sacerdotes y el hecho de que sus enemigos, los padres paúles, fueran «en su totalidad» peninsulares. Asimismo, se menciona la participación de Beyro en una Asamblea regionalista, lo que sin duda hace referencia al mitin regionalista celebrado un año antes en cuyo transcurso el sacerdote pronunció un destacado discurso ${ }^{44}$. Con esto comienza a quedar meridianamente claro que, tal y como apuntaba el diario El País, existía un trasfondo político e ideológico tras lo que parecía ser un mero conflicto eclesiástico. Además, el reportaje de La Correspondencia de España asegura que la multitud, agolpada frente al Seminario, en el mencionado ex convento de Santo Domingo, comenzó a «dar gritos de ¡Fuera los intrusos! ¡Viva el clero canario!, al mismo tiempo que apedreaban los balcones y puertas», asegurando que «se atribuye gran importancia á lo ocurrido por la significación que tiene, juzgándose que no se trata de una cuestión de apasionamiento religioso, sino de algo más grave y más hondo» ${ }^{45}$.

Como puede observarse, la prensa madrileña estaba al tanto de las ramificaciones políticas del enfrentamiento existente en la Iglesia tinerfeña. El citado medio estimaba que había un conflicto más profundo detrás de lo ocurrido. Y sin duda, parece apuntar a un choque en el que las ideas regionalistas de los sacerdotes sancionados habrían tenido un considerable peso. Se evidencia, pues, el conflictivo momento existente en Canarias en que la lucha entre partidarios de mantener

43 Idem.

44 «La Asamblea y la prensa madrileńa» (15 de mayo de 1908). La Opinión, n. . 4719, p. 1.

45 "Graves desórdenes en Tenerife» (29 de mayo de 1909). La Correspondencia de España, n. ${ }^{\circ} 18.735$, p. 3 . 
la unidad provincial y divisionarios protagonizaba el debate político. Un contexto de crispación en el que el regionalismo era planteado como una salida que podría contentar a todas las islas ${ }^{46}$. Así, la Iglesia no pudo mantenerse al margen de dicha conflictividad y la implicación de Santiago Beyro en el movimiento regionalista canario no fue bien acogida por aquellos elementos del clero probablemente más próximos a posturas centralistas.

De nuevo en La Correspondencia de España aparecería un artículo, reproducido por el diario El Tiempo que, firmado por Un católico imparcial, criticaba el hecho de que cierta prensa explique los sucesos de una manera que ha dado lugar a que algunos hayan "aprovechado para hablar de antiespañolismo ${ }^{47}$ en los disturbios. Por su parte, desde el campo político liberal, el también madrileño Diario Universal comentó los sucesos laguneros con la publicación, en primera página, de un artículo a cargo del militar, político y periodista canario Juan de Urquía. En el mismo, su autor aseguraba que los sucesos

... demuestran evidentemente que, no ya una parte, por fortuna, pequeña, del elemento burocrático, así civil como militar, sino también el eclesiástico, olvidando la misión de paz y caridad que Dios le tiene encomendada, como lema de su misión sobre la tierra, toman el país como si fuera una tribu á conquistar, y pretendiendo hacer mangas y capirotes á su antojo y voluntad, atropellan los fueros y preeminencias de la región, se mofan de sus usos y costumbres y tratan de vejar y desacreditar á sus hijos más preclaros y por los que el pueblo tiene especial predilección. Tal proceder es el que ha dado motivo justísimo para que se desarrollaran en la ciudad de La Laguna los lamentables sucesos... ${ }^{48}$.

De nuevo, una denuncia de una actitud entendida como colonialista, significativamente en las páginas de un medio madrileño. En este caso, una parte del elemento burocrático, y ahora del eclesiástico, es acusado de comportarse en Canarias de manera similar a cómo entonces se entendía era el proceder habitual en las colonias. De ahí la acusación de que actuaban con los isleños como si trataran con una tribu a conquistar. Y no menos contundentes fueron las palabras finales del autor:

Vean, pues, los seńores presidente del Consejo de Ministros y el señor ministro de Gracia y Justicia el remedio que ponen á tan grave mal, y no olviden que el pueblo canario es un fiero león de aguzadas garras, que no utiliza jamás, jamás, contra la Patria, porque siente por ella veneración, bien probada en su larga y honrosa historia; pero que, en cambio, le sirven para arrastrar hasta las aguas agitadas de sus pintorescos puertos, embarcándolos para la Península, á todos aquellos que corres-

46 Reyes GonzÁlez, Nicolás (1990): «Regionalismo y federalismo frente al divisionismo. Campaña de 'El Progreso' (Tenerife) en 1906». IX Coloquio de Historia Canario-Americana, vol. 1, pp. 907-938.

47 «Los sucesos de la Laguna» (18 de junio de 1909). El Tiempo, n. ${ }^{\circ} 1885$, p. 1.

48 Urquía, J. de (12 de junio de 1909). «Un pueblo contra el obispo y el provisor». Diario Universal, n. ${ }^{\circ} 2322$, p. 1 . 
ponden con groserías a su legendaria cortesía ó á los que traten de mermar en un átomo su sacrosanta libertad ${ }^{49}$.

Se comprueba, por tanto, que tanto prensa regional, como nacional, coincidieron en atribuir un claro matiz político a los sucesos laguneros. La acusación de trato discriminatorio hacia los isleños está patente en casi todos los medios que trataron lo ocurrido, incluidos aquellos que cubrieron los acontecimientos desde la capital espańola. Y el factor que parece clave es la vinculación de los protagonistas con el movimiento regionalista, entonces agrupado en torno al Ateneo de La Laguna, centro que, como se ha mencionado, fue calificado como filibustero y separatista por algunos sacerdotes peninsulares.

Sin embargo, para esclarecer estos sucesos se ha de rastrear aún más en los antecedentes, por lo que en el siguiente apartado se procede a analizar los conflictos que la prensa recogió durante los meses previos al motín del 27 de mayo. Con ello se pretende completar el bosquejo de las posibles razones y causas de fondo que dieron lugar a este conflicto de innegables connotaciones políticas.

\section{PROLEGÓMENOS DEL CONFLICTO}

Hasta el momento se han citado algunas de las causas directas que la prensa del momento citó como desencadenantes de los disturbios. Pero estas no fueron las únicas, tal y como se evidenciará más adelante. Así, si nuevamente se consulta la prensa de la época, puede apreciarse la buena acogida que tuvo el mencionado sermón que pronunció Santiago Beyro con motivo del día de la Cruz, esto es, el 3 de mayo de dicho 1909. Sobre el mismo el periódico La Opinión asegura que el sacerdote procedió a «entonar un canto hermoso, sublime, lleno de amor y de fé á la gran Patria española, y a este nuestro solar, Tenerife» ${ }^{50}$.

En el transcurso del mismo, Beyro definió lo que entendía por regionalismo canario, explicando que el regionalismo «á que aspiramos, no engendra el menguado propósito que algunos suponen de un desafecto á España, nuestra Patria», añadiendo el periódico que "probado se halla, bajo muchos conceptos, el amor de Beyro y de este pueblo á la madre Patria, para que esos espíritus ruines sembrados de discordias, profanen, torciéndolas, las aspiraciones de un pueblo noble, honrado, patriota, que solo anhela su grandeza y la de la Patria.... ${ }^{51}$. Sobre dicho sermón, un oyente presente en la Iglesia aseguró que al

Doctor Beyro, podrá discutirse si el púlpito, la tribuna sagrada, destinada a los asuntos ultraterrenos, es o no lugar para esbozar cuestiones políticas y estimular

\footnotetext{
49 Ibidem.

50 «Santa Cruz, en fiestas» (5 de mayo de 1909). La Opinión, n. ${ }^{\circ}$ 5007, p. 1.

51 «Santa Cruz, en fiestas» (5 de mayo de 1909). La Opinión, n. ${ }^{\circ}$ 5007, p. 2.
} 
al auditorio [...] a seguir tal o cual tendencia profana, pero no su amor a Espańa y su predilección por la isla que le vio nacer ${ }^{52}$.

Con ello parece ser que se pretendía salir al paso de las acusaciones de quienes cuestionaban el españolismo del padre Beyro, asegurando además que «es un regionalista, pero un regionalista especial, excento [sic] de aspiraciones interesadas...». Todo esto nos muestra que tanto Beyro como los periodistas que le enaltecen estaban esforzándose por explicar que su regionalismo no entraba en contradicción con el patriotismo espańol. Algo que no sería necesario de no existir suspicacias y acusaciones de separatismo o desafecto hacia quienes habían comenzado a propugnar la autonomía del archipiélago canario. Ya el político y escritor catalanista Juan Maluquer y Viladot había expresado en 1906 lo siguiente:

Negar que comienzan a dibujarse en Canarias tendencias regionalistas, no concretadas aún, pero que las nota quien desea enterarse de verdad del sentir de un pueblo, sería una tontería el ocultarlo, y buena prueba es de ello el hermoso libro del señor de Ossuna, El regionalismo en las Islas Canarias ${ }^{53}$.

Pero lo cierto es que el recelo hacia la llegada de elementos de la Península no había comenzado en 1909 ni durante la formación de la cultura política regionalista entre 1906 y la Asamblea de mayo de 1908. De hecho, los dos sacerdotes protagonistas de los sucesos aquí estudiados habían expresado sus reservas al respecto desde tiempo atrás. En concreto, José Rodríguez Moure, quien ante la llegada de la noticia de la pérdida de Cuba y Filipinas no dudó en afirmar cosas como las siguientes:

Don Silverio, no llore usted la pérdida de Filipinas y Cuba, porque era una desgracia inevitable, llore sí por la suerte que le espera a nuestras Islas. [...] Cuando un padre tiene un hijo guapo y otro feo todo lo que ama y distingue al primero, desaira y abandona al segundo, pero si pierde al guapo, «las zalamerías tribútaselas aumentadas al fenómeno [...]. A esto están condenadas nuestras Canarias. Los ratones, levantadas las heras de Cuba, Puerto Rico y Filipinas, se nos meterán por las puertas tras algunas pesetas que nos traigan algunos cosecheros de los nuestros que también fueron a la recolección y que vendrán de grandes tíos con pujos de orden y moralidad. Los peninsulares hasta la fecha nos han mirado con desprecio, no producía nuestro suelo todo el oro que apetecen sus uńas; pero como no les quedo ya otro campo a su rapacidad, dirán que es lo mejor y más hermoso, nos harán mimos y nos dirán el bebé, porque para ellos aunque feos somos los únicos hijos explotables, pues ya se murieron nuestras hermanas guapísimas y ricas, y como somos el último cuarto de la casa nacional que les quedo, convertirán nuestras pobres Islas, en la cocina en que se condimenta la bazofia que les sabrá ahora a pasteles de pavo

52 «El día tres» (5 de mayo de 1909). El Pais, diario liberal, n. ${ }^{\circ} 291$, p. 2.

53 Maluquer y Vilado, J. (1906). Recuerdos de un viaje a Canarias. Barcelona: Imprenta de Henrich y Compañía, p. 140 y ss. 
trufado, y en ellas fabricarán las letrinas en que arrojen todo lo que en la península tengan por inútil y digno de cloaca ${ }^{54}$.

Con ello, Rodríguez Moure expresaba su temor porque la pérdida de las últimas colonias provocase un interesado giro hacia Canarias así como la llegada desde la península de individuos de cualquier condición. Esta última cuestión, la inmigración peninsular a Canarias, parece que se había convertido en motivo de preocupación para el sacerdote lagunero pues a sus anteriores palabras añadió lo siguiente:

Raro es el vapor que no trae pasaje de empleados para Canarias en estos últimos tiempos. Gobernadores, generales, obispos, segundos cabos [...] pero todo esto pasó a la historia, hoy todo viene desde allá, lo bueno y lo malo barajado en pestífera aleación y lo mismo manda el gobierno a un capitán general como a un portero de las oficinas de hacienda y al igual viene un obispo como el cura de Chipude [sic], y como a la gente del país sólo le dejan las cargas ya va abriendo el ojo, y renegará de España en la misma forma que lo hicieran las colonias americanas ${ }^{55}$.

En dichas afirmaciones Rodríguez Moure parecía estar insinuando que, en Canarias, al igual que en las perdidas colonias americanas, la llegada de elementos de la Península para ocupar incluso los menos cualificados puestos de trabajo podía dar lugar a tendencias separatistas.

Por otra parte, Santiago Beyro protagonizó otro episodio polémico en diciembre del año 1900, cuando en un acto sin mayor importancia como era la bendición de la bandera de la Cruz Roja, pronunció un sermón ante una representante de la Reina-Regente, a la cual solicitó que se le transmitiera la siguiente súplica:

Decid á la egregia Señora que rige los destinos de nuestra Nación [...] que nosotros á lo que aspiramos es á que se respeten nuestras tradiciones y nuestra nativa idiosincrasia; que no nos mande aves de rapiña que desgarren nuestro pecho y beban con fruición nuestra sangre, baldonen nuestras hermanas y siembren la maldita simiente del libertinaje en nuestro hogar, nunca profanado, sino que ya que como á hermanos los recibimos como hermanos nos traten y consideren y no como á parias ${ }^{56}$.

Tales palabras llegaron a oídos de la prensa de Madrid donde fueron interpretadas como antiespañolas, de manera que el periódico El Liberal aseguró que «... hemos oído por segunda vez, en menos de seis meses, que desde el pulpito de una de las principales iglesias de esta población, por uno de los sacerdotes de más prestigio en el país [...] se hayan empleado frases durísimas contra la madre patria y

54 Rodríguez Moure, J. (junio-julio de 1985). "Cavilaciones sobre la pérdida de Cuba». Revista Oeste de África (ROA), núms. 1-2, pp. 43-46.

55 Idem.

56 «La bola de nieve. Para "El Liberal” de Madrid»(8 de enero de 1901). La Región Canaria, n. 222 , p. 1. 
aquellos de sus hijos que han nacido en la Península.» Además, desde el periódico madrileño se exigió a las autoridades tomar las medidas necesarias para impedir tal "propaganda hecha en Santa Cruz de Tenerife desde el pulpito" "57.

Por fortuna para Beyro, el entonces Capitán General de Canarias, Ignacio Pérez Galdós, decidió hacer la vista gorda ante las polémicas palabras del sacerdote tinerfeńo, sobre las cuales llegó a decir que «no hay que tomar los hechos de esa forma torcida en que se han tomado, sino en su verdadero sentido, porque lo que don Santiago Beyro quiso hacer llegar a la reina, no fue otra cosa sino el que no nos enviara más aves de rapiña, porque...nosotros aquí las tenemos de sobra $\aleph^{58}$.

Con esos antecedentes y la mencionada implicación en el movimiento regionalista, no debe extrañar que ambos sacerdotes mantuviesen tensas relaciones con un clero peninsular con el que competían por ocupar plazas claves en la jerarquía eclesiástica. Esto quedó claro un año antes de los disturbios, cuando la candidatura de Santiago Beyro a ocupar el cargo de Arcediano de la Catedral de Tenerife, pese a contar con el apoyo del Cabildo de Tenerife y de casi todas las corporaciones locales de la isla, que se dirigieron telegráficamente al obispo Rey Redondo, se vio frustrada al decantarse este último por Florentino Montañez. La prensa aseguró al respecto que «en el país -Tenerife, La Palma, La Gomera y El Hierro- existe la idea de que en el Seminario, y fuera de él, dominan ciertos prejuicios contra los paisanos, ó cuando menos, que se atiende poco á que constituya la mayoría el clero insular ${ }^{59}$. Pero a la lógica decepción siguió la denuncia en los términos más contundentes:

Mas no hemos de callar nosotros, hijos de este país esclavizados por el egoísmo de algunos nocivos y perturbadores elementos, la protesta que nace espontánea en nuestros pechos, al presenciar las pretericiones, despojos é injusticias de que están siendo víctimas los paisanos [...]. No es esta la primera vez ni ha de ser la última, en que los hijos del país se vean postergados y derrotados por la ambición y la soberbia de los que parecen disfrutar aquí de irritantes privilegios, usurpando, escalando muchas veces, con la ganzúa de su egoísmo y osadía, los altos puestos oficiales que pudieran servir para premiar el mérito de honorables compatriotas, al olvido, cuando no al desprecio relegados [...] es este un país perdido, donde solo los Chavetas, paules y demás caterva mística encuentran amparo y protección. Los demás, los hijos del país, á emigrar... ${ }^{60}$.

De esta cita pueden sacarse varios datos de interés: de una parte, que la prensa republicana se había alineado con los sacerdotes isleños de manera abierta. Prensa que no solía ocultar sus críticas al clero, caso del diario El Progreso. Por otra parte, se había consolidado la denuncia de la discriminación hacia los «hijos del país», esto es, hacia los isleños. Y, además, muestra como se había consolidado una

57 «Eso nos faltaba» (31 de diciembre de 1900). El Liberal, n. ${ }^{\circ}$ 7.756, p.1.

58 Jurenito, J. (1983). «Don Ignacio Pérez Galdós, capitán general de Canarias (I)». Aguayro, n. ${ }^{\circ}$ 150, pp. 31-32.

59 Añaza, J. de (25 de mayo de 1908). «El asunto Beyro». La Opinión, n. ${ }^{\circ} 4727$, p. 1.

60 «Por los hijos del país» (13 de mayo de 1908). El Progreso, n. ${ }^{\circ}$ 811, p. 2. 
dicotomía entre dichos hijos del país y los clérigos peninsulares (Chavetas, paúles...). Un enfrentamiento que va a continuar en el tiempo, hasta desembocar en los graves disturbios del año 1909, que, sin duda, fueron el punto culminante de esta tensión latente en el seno de la Iglesia y de la sociedad.

\section{¿ALIANZA ENTRE CATÓLICOS Y ANTICLERICALES ISLEÑOS FRENTE AL CLERO PENINSULAR?}

Otro aspecto a analizar respecto a los disturbios laguneros es si los mismos estuvieron vinculados al movimiento anticlerical existente en las islas. Por lo pronto, cabe destacar que los sectores anticlericales compartían circunstancialmente enemigo con el clero canario, a saber, los cada vez más numerosos padres paúles. Así es que en la prensa se produjo una alianza entre elementos anticlericales y católicos defensores del padre Beyro y del clero canario, en general.

Ejemplo de ello es el artículo aparecido en las páginas del semanario Barreno y... ¡Fuego!, órgano de la juventud radical, y con el que dicho periódico entraba de lleno en la batalla interna que se vivía en la diócesis nivariense. En el mismo, tras afirmar que «La horda impetuosa de Paúles, irrupción funesta que ya nos inquieta demasiado, no cesa en su campaña repugnante contra la virtuosidad y prestigio del doctor Beyro...», asegurando que «un paúl que se nombra Anselmo Andrés» puso en evidencia la lucha "fratricida» que se estaba produciendo en el seno de la Iglesia de dicha ciudad, "una lucha, desigual y cobarde» ${ }^{61}$.

Por su parte, en enero de 1909, el mismo ańo en que tuvieron lugar los sucesos aquí analizados, el diario republicano El Progreso denunciaba lo que calificaba como «invasión peligrosa», por la llegada de órdenes religiosas que estaban copando la educación de las clases altas. Al respecto informaba sobre cómo «los reverendos padres de San Vicente, que al poco tiempo acapararon todas las cátedras del Seminario conciliar, antes servidas por sacerdotes del país». Asimismo, denunciaba que en las islas «vamos por el mismo camino de las colonias, y que de seguir las cosas así no se tardará mucho tiempo en ver á esta provincia convertida en un nuevo Archipiélago filipino»" ${ }^{62}$. Estamos, de nuevo, ante la denuncia del trato colonial recibido por Canarias y sus habitantes, un tema siempre presente en la prensa isleña durante toda esta primera década del siglo xx y que ahora tenía su proyección en el ámbito religioso. Finalizaba el mencionado periódico afirmando que «estamos amenazados de una tremenda invasión de instituciones y cofradías religiosas, y deber nuestro es avisar á los incautos el peligro».

Como puede apreciarse, no faltó la denuncia del creciente poder de las órdenes y agrupaciones religiosas y en especial de su control del sistema educativo. Un

${ }^{61}$ Salmos (27 de junio de 1908): «Beyro y los Paúles». Barreno y ... jFuego!, órgano de la juventud radical, n. ${ }^{\circ} 4$, p. 2.

${ }^{62}$ SAncho (18 de enero de 1909). «Padres y padritos». El Progreso, n. ${ }^{\circ} 1014$, p. 1. 
fenómeno común en todo el estado y que tendría precisamente su punto culminante en los sucesos de la Semana Trágica de Barcelona, en los que las escuelas religiosas se convirtieron en objetivo de ataques por parte de las masas subalternas ${ }^{63}$. Al respecto, no hay que perder de vista que los acontecimientos de la capital catalana tuvieron lugar tan solo unos meses después de los incidentes de La Laguna. Y si bien no es posible hacer comparaciones entre ambos sucesos, no deja de ser llamativo que en las calles de La Laguna también fueran atacados Palacio episcopal y Seminario, estando este último a punto de ser incendiado.

Pero esta creciente conflictividad entre el clero canario y los sacerdotes llegados desde la Península no estuvo restringida a La Laguna. En los meses anteriores se produjeron diversos incidentes en distintos puntos de la geografía canaria. A continuación, se mencionan algunos de ellos como ejemplo del ambiente de crispación que se estaba viviendo en diversas parroquias insulares.

La hemeroteca nos ofrece un rosario de incidentes, en los que la población atacó a los sacerdotes foráneos que, como se indica en muchas ocasiones, solían ocupar sus plazas desplazando a isleños. Un primer ejemplo de ello es lo ocurrido en Güímar, donde el párroco se negó a acompañar el féretro de un fallecido hasta el cementerio, al parecer por la inquina que le guardaba por ser un conocido suscriptor de los diarios republicanos El Progreso y Barreno y... iFuego! ${ }^{164}$. La actuación del cura dio lugar a que la casa parroquial fuese «apedreada; hecho bárbaro que nosotros reprobamos, pero que denota la excitación producida por el proceder incorrecto y reprobable del Sr. Párroco de Güímar» ${ }^{65}$.

Asimismo, el semanario Barreno y... iFuego! dirá al respecto de «lo ocurrido en pasadas semanas entre el vecindario de Güimar y su cura ecónomo don Manuel Cortés...» que «es una judiada que no tiene precedente en la historia isleña.» Añadiendo en un tono claramente irónico que «rebosante de amargura su corazón, ha embarcado para la Península en busca de lenitivo para su inmensa pena ${ }^{66}$. Significativamente el periódico La Laguna, órgano de la Diócesis, considerado por la prensa republicana como el medio donde «está la flor y nata del clericalismo filipino que padecemos en esta tierra ${ }^{67}$, lamentó la marcha del citado cura, lo que ahonda la impresión de enfrentamiento entre ambos sectores.

Incluso en pequeñas localidades, como el caso de los Silos, estalló el conflicto. En esa localidad del norte de Tenerife se afirma que el párroco, «el ilustrado sacerdote del país Sr. Pérez Remón, va á ser relevado por un paúl, protegido del Obispo. El pueblo está indignado con este hecho, y se anuncia una protesta tan ruidosa y elocuente como la última de La Laguna ${ }^{68}$. Es decir, de nuevo un párroco canario siendo sustituido por un paúl. Y también en Icod de los Vinos, localidad donde:

\footnotetext{
${ }^{63}$ Martínez, G. (2009). Barcelona rebelde. Guía histórica de una ciudad. Barcelona: Debate.

64 «Intemperancias de un párroco» (29 de marzo de 1909). El Progreso, n. ${ }^{\circ} 1069$, p. 2.

65 «Sacerdote violento» (30 de marzo de 1909). La Opinión, n. ${ }^{\circ} 4978$, p. 1.

${ }^{66}$ Cortesanía (17 de abril de 1909). «Los negros». Barreno y... jFuego!, n. ${ }^{\circ} 46$, p. 2.

67 «Dios los cría..." (1 de abril de 1909). El Progreso, n. ${ }^{\circ} 1072$, p. 2.

68 "Místicas» (3 de junio de 1909). El Progreso, n. ${ }^{\circ} 1123$, p. 2.
} 
los frailes han estado también á punto de ser lynchados (sic), por el pueblo. Promovió el conflicto el misionero P. Martel, que anunció un sermón para hombres solos, y dijo tales enormidades contra éstos, que los fieles se amotinaron y la emprendieron á silletazos con el atrevido predicador. Este tuvo que salir huyendo del pueblo.

En conclusión, la prensa nos muestra que los incidentes se estaban repitiendo por distintos puntos. De ahí que el periodista afirmara que los frailes «están haciendo de las suyas en toda la isla, ofendiendo los sentimientos del país» ${ }^{69}$.

Pero la conflictiva presencia de los padres paúles no iba a verse ni mucho menos limitada a la isla de Tenerife y por estas mismas fechas estallaron polémicas en otras islas. Como muestra, en la isla de La Palma, el padre Alpuente, superior de los padres paúles en la capital palmera, protagonizó un escándalo al acusar de corrupción de menores a una sociedad de recreo: el Real Nuevo Club. La directiva de dicha sociedad decidió llevar a los tribunales al mencionado paúl, que finalmente y para evitar mayor escándalo emitió una nota de retractación pública. Al respecto, la prensa no dudaría en afirmar que los frailes, «tanto en La Laguna como en La Palma vienen sembrando la discordia entre los fieles» ${ }^{70}$.

Ante todos estos sucesos, el semanario Barreno... y iFuego! no dejó pasar la ocasión para agradecer, con sorna, el que los clérigos peninsulares estuviesen contribuyendo a fortalecer su propaganda anticlerical: «La verdad es que BARRENO no se puede quejar de su buena suerte: de todas partes le están saltando colaboradores. Siga la razzia. Esto marcha viento en popa $»^{71}$.

Lo anterior pone de manifiesto la convergencia coyuntural que se estaba produciendo entre sectores anticlericales y católicos isleños en su conflicto con los frailes peninsulares. Esto debe ser puesto en relación con la formación del movimiento regionalista y su expresión electoral: Unión Patriótica. Este regionalismo canario, inspirado en la Solidaritat Catalana, iba a seguir los pasos de dicha candidatura catalanista, uniendo en sus filas desde a republicanos hasta católicos tradicionalistas, coaligados de manera circunstancial con el objetivo de derribar el caciquismo ${ }^{72}$. En Cataluña la misma Solidaritat había agrupado en sus candidaturas tanto a católicos como a anticlericales, unidos por su común catalanismo:

En el criterio de Cambó, la Solidaridad Catalana, que había reunido en el invierno de 1905-6 a todos los partidos autonomistas -integristas, carlistas, Unió Catalanista, Lliga y Esquerra, parte de la Unión Republicana, federalismo-, podía llegar a suplantar la polarización conservatismo-liberalismo del sistema de Cánovas por el enfrentamiento regionalismo-socialismo. Tal pretensión [...] suponía no obstante una difícil claudicación de las demás reclamaciones programáticas de cada uno de sus miembros. Y, en concreto, requería un acuerdo de aconfesionalismo entre

\footnotetext{
69 Idem.

70 «Escándalo en La Palma» (12 de abril de 1909). El Progreso, n. ${ }^{\circ}$ 1080, p. 2.

71 «... Y llueve» (17 de abril de 1909). Barreno y... ;Fuego!, n. ${ }^{\circ} 46$, p. 2.

72 Karboune Rodríguez, Said (2019). La construcción del movimiento regionalista en Cana-
} rias: 1898-1910. Trabajo final de Grado. Grado en Historia [inédito]. 
grupos católicos y grupos defensores de la política anticlerical. [...] Sarda i Salvany insistió en ello en junio, al advertir en la Revista Popular cómo el entendimiento solidario acogía a «monárquicos y republicanos, carlistas y alfonsinos, creyentes y librepensadores» ${ }^{73}$.

De manera similar, el movimiento solidario canario iba a agrupar en sus filas desde liberales como el presidente del Ateneo de La Laguna, Benito Pérez Armas, hasta católicos como Andrés de Arroyo y González de Chaves (1883-1968) ${ }^{74}$ y en estas circunstancias, es muy probable que el conflicto en torno a la figura de Santiago Beyro les sirviera de elemento aglutinador. La nación para el caso catalán o la región para el canario, así como la defensa de sus hijos más destacados, pasaban a estar por encima de lo demás, incluso de la religión. Sin duda, un punto de inflexión en la asunción del sistema liberal burgués y de uno de sus pilares: el nacionalismo ${ }^{75}$. Prueba de lo afirmado es lo que comentaba un periódico autonomista respecto al movimiento regionalista isleño: «Bajo la denominación de "Unión Patriótica" hay hombres de todos los partidos, tanto de los que turnan en el Gobierno de la nación como de los que laboran en las oposiciones; y tampoco desconocemos las ideas, abiertamente opuestas, que en materias religiosas alientan las prestigiosas personalidades que integran la "Unión" $»^{76}$.

Así, ante los escándalos que se estaban produciendo en la Iglesia, los sectores anticlericales de dicho movimiento no dudaron en expresar su satisfacción de la manera más mordaz posible, como fue el caso de un esclarecedor artículo aparecido en el diario El Progreso:

Felicitamos á la camarilla epíscopal de La Laguna por sus medidas contra los curas que no quieren ser instrumentos del caciquismo y la alentamos para que continúe ayudándonos á emancipar conciencias aldeanas y sacrificando á los sacerdotes virtuosos y queridos en aras de las exijencias (sic) de adinerados seńores. Adelante los mandarines de la Diócesis. Ellos por su camino y nosotros por el nuestro, hemos de encontrarnos, convergiendo a un mismo fin: el de arrancar la venda de la fe en las ciudades y en la aldea. Duro, muy duro con los clérigos que se niegan á ser aliados de los tiranuelos rurales. Sobre todo si son clérigos nacidos en el país... ${ }^{77}$.

Estamos por lo tanto ante un conflicto entre católicos que estaba siendo explotado por sectores partidarios de la secularización, cuando no abiertamente

73 Andrés-Gallego, José (1973). «Transformación política y actitud religiosa del gobierno largo de Maura (1907-1909)». Revista de estudios políticos, núms. 189-190, pp. 150-151.

${ }^{74}$ Heredero Gascueña, V. (2006). Andrés de Arroyo y González de Chaves (1883-1968). Santa Cruz de Tenerife: Fundación Canaria Víctor Zurita-Soler/Gobierno de Canarias.

75 ANDERSON, Benedict (1993). Comunidades imaginadas. Reflexiones sobre el origen y la difusión del nacionalismo. México: Fondo de Cultura Económica.

${ }^{76}$ Estrada Pérez, J. (19 de julio de 1909). «Protección á los canarios». El Progreso, n. ${ }^{\circ} 1160$, p. 1 .

77 «Camarilla episcopal» (1909). El Progreso, n. ${ }^{\circ}$ 1106, 13 de mayo, pp. 1-2. 
anticlericales. Liberales, republicanos y movimiento obrero hacen frente común con los defensores de Beyro y Rodríguez Moure, en las críticas contra el obispo y los paúles. Algo que queda meridianamente claro al leer lo expresado por el mismo medio republicano:

En las columnas de este mismo periódico, que tan gallardamente embiste contra todos los convencionalismos de esa hipócrita familia clerical, se ha hecho la más noble de las defensas de dos dignos sacerdotes del país; buena prueba de ello es el procesamiento que pesa sobre Leoncio Rodríguez, la única víctima de la suspensión de Beyro y Moure... ${ }^{78}$.

Estas circunstancias muestran el complejo panorama político que se estaba viviendo en el archipiélago canario en estos momentos finales de la primera década de siglo. Regionalismo, anticlericalismo, denuncias de trato colonial y otros temas de notable importancia se conjugaron en esta batalla entre el clero canario y el peninsular.

Fue tal el ambiente de crispación y enfrentamiento, que incluso los padres paúles llegaron a reclamarle al gobernador que les suministrase protección ante sus temores de ser atacados en las semanas posteriores a los disturbios de La Laguna, algo que la prensa republicana interpretó como una forma de «amedrentar á los laguneros, rodeándose de fuerza para aparecer como protegidos del gobierno $»^{79}$.

En definitiva, vemos como los enfrentamientos se repiten por diferentes puntos de la geografía isleña y como en casi todos los casos estaban implicados los mencionados paúles, que se habían ganado la animadversión local, hasta el punto que algunos medios no dudaron en afirmar que «con la pérdida de algunos de esos elementos como los padres Paules iríamos todos ganando en tranquilidad, y en la misma ciudad de La Laguna [...] la ausencia de esos padres se celebraría hasta con repiques de campanas» ${ }^{80}$.

\section{POSTRIMERÍAS DEL CONFLICTO}

Durante los meses siguientes a lo ocurrido en La Laguna, no faltaron los análisis desde diversos sectores de la sociedad tinerfeña. Uno de los protagonistas directos de los sucesos, Benito Pérez Armas, publicó en prensa unas reflexiones en las que justificaba lo ocurrido en La Laguna con el argumento de que

la voz de los isleños debe levantarse para conseguir un poco de atención. Los sucesos despiertan la curiosidad, tornan hacia las Islas las miradas, quizá existan dolo-

78 Estrada Pérez, J. (19 de julio de 1909). «Protección á los canarios». El Progreso, n. ${ }^{\circ} 1160$, p. 1 .

79 «Frailes asustados» (17 de junio de 1909). El Progreso, n. ${ }^{\circ} 1134$, p. 2.

80 «La diócesis» (6 de marzo de 1909): El Progreso, n. ${ }^{\circ}$ 1052, p. 1. 
rosos recuerdos de los grandes desastres nacionales [...] para que sobre las olas del mar llegue á la Península el eco de nuestro juicio [...] acreedor al análisis, a exámen de aquellos á quienes la Patria confiere la dirección de sus destinos ${ }^{81}$.

Como puede observarse, Pérez Armas interpreta los disturbios laguneros como un necesario alzamiento para que el gobierno central preste atención a los problemas de Canarias. Tras ello realiza un análisis histórico donde compara la manera en que España administró sus territorios ultramarinos con los de otras potencias, asegurando que: «en todas las naciones poderosas, la sociología ha enseñado [...] que no se puede regir del mismo modo todos los pueblos agrupados bajo un pabellón soberano, sobre todo si tienen distintas condiciones étnicas y están separados del territorio continental». Cosa que, según Pérez Armas, España no comprendió, lo que llevó a la pérdida de las colonias. Para concluir afirmando:

Hemos querido decir que Canarias no puede continuar regida por el capricho de unos cuantos, á espaldas de su voluntad; que el personal -autoridades, etc.- que venga a estas islas, debe ser cuidadosamente escogido para que sepa mandar sin extralimitarse, sin herir; que las costumbres, las características, el amor propio, buenos ó malos, en cuanto no sean incompatibles con el interés nacional -que nunca lo son- deben respetarse; que la legislación se debe acomodar á las condiciones geográficas y sociales del Archipiélago ${ }^{82}$.

Estamos pues, ante un alegato en defensa de la autonomía de Canarias aprovechando los disturbios, sin duda una manera bastante hábil de sacar rédito político a lo acontecido. Y es que esta utilización política de los sucesos de La Laguna llevó a algunos a realizar análisis de gran interés, como el de un artículo aparecido bajo pseudónimo ${ }^{83}$ que, además de destacar el protagonismo de los obreros laguneros, llegó incluso a afirmar que se trataba de una revolución a pequeña escala:

¿Que fué la revolución francesa sino un alarido, bestial si se quiere, pero ahito de humanidad, del pueblo oprimido? ¿Qué son en la historia las revoluciones de Méjico, Servia, Rusia...? En pequeño la manifestación del Jueves á la noche fué una revolución ${ }^{84}$.

¿Fue esa la postura que adoptó el movimiento obrero? ¿Entendieron los disturbios como un acto revolucionario? Pues la respuesta puede que se encuentre en el primer número del semanario $E n M a r c h a^{85}$, que comienza a publicarse a las dos

${ }^{81}$ Pérez Armas, B. (1 de junio de 1909). «Enseñanzas y reflexiones». La Opinión, n. ${ }^{\circ} 5029$,

p. 1.

${ }^{82}$ Idem.

${ }_{83}$ Squilad era el pseudónimo empleado por el escritor Joaquín Estrada Pérez, tanto para firmar artículos en prensa como algunos trabajos literarios, por ejemplo: Aires de mi montaña (1908) o Risco abajo (1909).

${ }^{84}$ SQuilad (1 de junio de 1909). «La dictadura frailesca». El Progreso, n. ${ }^{\circ} 1121$, p. 1.

85 «De los tuyos te vendrán las pedradas» (7 de junio de 1909). En Marcha, n. ${ }^{\circ} 1$, p. 1. 
semanas de los sucesos de La Laguna. Este medio nos muestra una opinión mucho más crítica. De entrada, los redactores del mismo, anarcosindicalistas isleños, van a tildar de "multitud idólatra y fanatizada» a los laguneros que se manifestaron en defensa de Beyro y Rodríguez Moure. Si bien expresaban sus esperanzas de que estos disturbios fueran el principio de un «despertar». Sin embargo, consideraron a los mismos como «impropios de un pueblo consciente» por responder al deseo de «amparar contra unos sacerdotes los intereses particulares de otros sacerdotes». Con ello dejan clara su militancia anticlerical, considerando además, que esta protesta no beneficiaba al bienestar común.

De hecho, este medio anarcosindicalista considera que «por cuestiones entre eclesiáticos no merece la pena hacer el derroche de energías que los laguneros han desarrollado.» Es decir, se lamentan de que el pueblo lagunero haya salido a las calles en defensa de los sacerdotes Beyro y Rodríguez Moure y no de ideales progresistas. Un posicionamiento completamente coherente con la tradición anticlerical del movimiento anarquista. Incluso afirman que Beyro y Rodríguez Moure únicamente hubiesen sido merecedores el aplauso popular si, ante su suspensión, hubiesen renunciado a sus hábitos. Desde luego no parece que el movimiento obrero tinerfeño se implicase de manera organizada en estos acontecimientos, si bien no hay que olvidar que, por estas fechas, el republicanismo aún agrupaba a la mayoría de trabajadores $^{86}$. Por ello cabe interpretar el apoyo a las protestas y a los sacerdotes canarios expresado en medios republicanos como El Progreso o Barreno y... jFuego!, como una constatación de que ciertos sectores obreristas sí se implicaron en las mismas.

\section{¿ORIGEN DE LA EXPLICACIÓN INDEPENDENTISTA?}

Llegados a este punto, cabe preguntarse de dónde surge la interpretación de los disturbios como expresión de un movimiento separatista canario. Al respecto hay un documento clave, que podría estar en el origen de la misma. Se trata de Huellas del Tiempo, las memorias de Domingo Cabrera $\mathrm{Cruz}^{87}$, uno de los fundadores del Ateneo de La Laguna, amigo de Benito Pérez Armas y testigo directo de los sucesos aquí tratados. En dichas memorias dedica un apartado a lo que él denomina «motín en La Laguna»" ${ }^{88}$, en el que da su explicación de los sucesos, protagonistas y contexto político. Del mismo se han extraído todas las citas mencionadas a continuación. Así, asegura que "existía en Canarias un sentimiento regional que se exteriorizaba en ligeros altercados cuando las disposiciones centrales herían los intereses

${ }^{86}$ Felipe Redondo, J. de (2005). «De la nación a la ciudadanía: el Partido Popular Autonomista [Santa Cruz de Tenerife, 1901]». En La Torre: Homenaje a Emilio Alfaro Hardisson. Santa Cruz de Tenerife: Artemisa Ediciones, pp. 205-226.

${ }^{87}$ Alonso, M. ${ }^{a}$ R. (1979). «Páginas de literatura canaria (2) Domingo Cabrera, periodismo y novela». Aguayro, n. ${ }^{\circ} 116$, pp. 026-027.

88 Cabrera Cruz, D. (1973). Huellas del Tiempo. Caracas, Venezuela: Editorial Arte, pp. 34-45. 
del archipiélago». Además, añade que tras la pérdida de las colonias comenzaron a llegar a las islas funcionarios «advenedizos que entraban por el muelle como por tierra recién conquistada», a los que asegura "designábamos con el nombre de godos».

Estas afirmaciones dan idea de la conflictividad existente entre isleńos y peninsulares, que, según Cabrera Cruz, se trasladó al seno de la diócesis. Asegura el autor que, siendo él director del Hotel Aguere, pudo conocer personalmente al provisor Sansó, al estar este último alojado en dicho establecimiento. Fue entonces cuando comprobó de primera mano los "prejuicios contra el clero isleńo» que albergaba Sansó. Sea como fuere, lo cierto es que, en sus memorias, Domingo Cabrera reproduce un dialogo que habría mantenido con el provisor Sansó, en que supuestamente este le dijo que Beyro debería hacer «más labor parroquial y menos discursos separatistas». Acto seguido Cabrera Cruz cita la ya mencionada polémica protagonizada por Santiago Beyro a raíz de un sermón ante un representante de la ReinaRegente: «Mandadnos, Señora, hombres honestos y no buitres que chupen nuestra sangre y ultrajen nuestras mozas».

Sin embargo, el resto del relato de lo sucedido coincide con lo recogido por la prensa de la época, por lo que ciertamente no parece aportar mayores evidencias sobre el supuesto carácter independentista de la protesta. Eso sí, en su descripción, Cabrera Cruz muestra una protesta violenta, que en sus propias palabras: «era algo aterrador. La calle ardía. Hubo pánico. Temor a una noche trágica». Pero quizá, lo más interesante del relato realizado en este libro sea lo referente a la supuesta comparecencia de Sansó ante el Ministerio de Justicia, en Madrid, donde habría descrito lo ocurrido en La Laguna como «un levantamiento separatista apoyado por las autoridades locales». Al parecer, siguiendo con lo anotado por Cabrera Cruz, fue gracias a la moderada actuación del entonces juez de La Laguna, el peninsular Carlos Lagos, que se evitó llevar a prisión a muchos laguneros. Domingo Cabrera termina su descripción de lo acontecido en aquellas ya lejanas jornadas afirmando que el motín lagunero «fue una llamada a la comprensión de los problemas políticos y religiosos de nuestra isla, una advertencia a los rectores espirituales de la Diócesis que no toleren el atropello de los sentimientos regionales por funcionarios godos a sus órdenes».

Cabe especular que, por las fechas en que esta obra fue publicada, 1973, pudo haber tenido un cierto impacto en los movimientos nacionalistas del momento, siendo el origen de las referencias al motín lagunero en los documentos mencionados al comienzo del trabajo. No hay que olvidar que dichos movimientos nacionalistas, buscaban construir un relato anticolonial como alternativa a la historia insular oficial. De todos modos, el libro del intelectual Domingo Cabrera debe ser tomado con precauciones, pues al tratarse de unas memorias publicadas unos 60 años después de los sucesos, sus recuerdos pueden estar mediatizados por el paso del tiempo y las experiencias vitales del autor. De ahí que probablemente estamos ante una proyección hacia el pasado del creciente ambiente de nacionalismo que se vivía entre la colonia canaria en Venezuela. Al respecto, no hay que olvidar que era en dicho país donde residía el autor y que fue en Caracas donde se editó Huellas del Tiempo. Sea como fuere, se trata de la fuente más inclinada hacia una interpretación separatista de los sucesos de La Laguna, que irónicamente habría tenido su origen en la más que probable exageración de los acontecimientos por parte del provisor Manuel Sansó. 


\section{CONCLUSIONES}

Frente a la imagen de los disturbios de La Laguna como una rebelión independentista que puede leerse en algunos textos del pasado siglo, el presente trabajo de investigación ha encontrado que es a la cultura política regionalista y al contexto político canario del segundo lustro del siglo $\mathrm{xx}$, al que deben vincularse los mismos. La prensa de la época nos muestra de manera clara la ausencia de motivaciones separatistas tanto en sus protagonistas como entre los manifestantes. Sin embargo, esto ha de ser matizado, pues como se ha ido citando, el conflicto interno de la Iglesia que dio lugar a los sucesos, estuvo caracterizado por el enfrentamiento que existía entre el clero isleño y el peninsular.

En la Iglesia, había surgido un conflicto por los cargos, ante la llegada de frailes desde Filipinas y Península, quienes, con el amparo del obispo, fueron logrando hacerse con los principales puestos de la diócesis. Ante tal panorama, el clero canario se sintió agraviado y sus quejas comenzaron a tener eco entre sus feligreses. Todo esto en un contexto en que la política canaria, en especial en Tenerife, era testigo de la formación de un movimiento regionalista que haría de la defensa de los hijos del país una de sus banderas. Es precisamente debido a este ambiente y a que, tanto Santiago Beyro como José Rodríguez Moure, estuviesen implicados en dicho regionalismo, que se explica que desde las filas de Unión Patriótica y su prensa afín, se cerraran filas en torno a ambos sacerdotes.

Por otro lado, estos sucesos dieron lugar a un fenómeno sui generis, la alianza circunstancial entre elementos católicos y anticlericales de las islas, quienes unieron sus voces para defender a Beyro y Rodríguez Moure frente a los padres paúles y el provisor Sansó. Esta alianza, en principio anti natura, nos revela como en dichos momentos, el regionalismo canario estaba comenzado a ser lo suficientemente transversal como para unir en sus causas a personas con puntos de vistas completamente opuestos en materia religiosa.

¿Todo esto puede tener una lectura separatista? Podría afirmarse que no, pues las referencias documentales reflejan que Rodríguez Moure y, muy en especial, Santiago Beyro, mostraron su españolismo en más de una ocasión. En este sentido cabe interpretar su pensamiento como una identidad dual, en la que su regionalismo canario no iba reñido con su lealtad hacia la entendida como «Madre Patria». Así pues, explicaciones de antiespañolismo como las que habría lanzado Sansó, parecen responder más a la intención de dañar el nombre de dichos sacerdotes que a la realidad de los hechos. Esto no quiere decir que no pudiese haber elementos vinculados a Secundino Delgado entre quienes protagonizaron estos sucesos. De hecho, la juventud del Ateneo coincidía en muchos aspectos con el pensamiento de Delgado, si bien no en sus objetivos: mientras que el primero quería una Canarias independiente, los regionalistas agrupados en torno al Ateneo luchaban por la autonomía del archipiélago.

En cualquier caso, estas son unas conclusiones abiertas a discusión y el presente trabajo de investigación no tiene como objetivo sentar una versión definitiva de los sucesos de La Laguna sino darlos a conocer y despertar el interés por investigar una etapa de nuestra historia contemporánea, que aún esconde temas dignos 
de estudio. Ejemplo de ello es lo analizado en este trabajo sobre el papel crucial que jugaron las mujeres laguneras en los acontecimientos. No ya como meras testigos sino como vanguardia de la protesta, tal y como se ha visto. Un tema que, si se estudia desde la perspectiva del género, daría para otro artículo. También a este respecto se podría seguir la estela de la investigación de Pilar Salomón ${ }^{89}$. De igual modo ha quedado patente la conexión con otros motines urbanos, que es como podría ser etiquetado lo acontecido en la ciudad de los Adelantados. El año 1909 estuvo marcado por revueltas urbanas de diversa índole que, en algunos casos se cobraron vidas y en otros no.

Asimismo, los sucesos de La Laguna de 1909 marcaron la vida social y religiosa de esta ciudad durante mucho tiempo. Sus protagonistas tendrían un lugar clave en la historia insular, pero el suceso como tal cayó en el más absoluto olvido. A esto podría haber contribuido la posterior etapa del obispado de Rey Redondo, cuyo papel en la conclusión de la construcción de la Catedral de La Laguna le ganó un lugar en la memoria de los católicos de Tenerife. Asimismo, la caída del movimiento regionalista, cuyos protagonistas acabarían sumándose a las filas de partidos estatales tras la ruptura de la Unión Patriótica, puede haber contribuido a que cayeran en el olvido, al igual que muchas figuras y eventos políticos de aquellos años.

En definitiva, aunque todavía queda mucho por estudiar y documentación por analizar (¿̨realmente Sansó declaró ante un tribunal de Madrid?), puede afirmarse que lo ocurrido en La Laguna respondió a un conflicto interno de la Iglesia con profundas implicaciones políticas. Dichas implicaciones ligan lo acontecido con la cultura política regionalista en boga. Mi intención ha sido la de clarificar los sucesos, a lo que espero contribuya este trabajo. Sin más, invito a todos los investigadores de las islas a profundizar en esta cultura política regionalista y a investigar el periodo, más allá del pleito insular. Este último conflicto, coetáneo a estos sucesos, puede ser un factor que ha contribuido a eclipsar otros fenómenos políticos y sociales, como los aquí estudiados. Quizá sea este el momento de hacer la microhistoria política de Canarias, dando a conocer acontecimientos que en su día tuvieron un notable eco y que marcaron a generaciones enteras. Sucesos que, pese a su carácter local, tenían claras resonancias nacionales.

RECIBIDO: 4-9-2020; ACEPTADO: 15-4-2021

89 Salomón ChéLiz, M.P. (2000). «Mujeres, religión y anticlericalismo en la España contemporánea: ¿para cuándo una historia desde la perspectiva de género?». En El Siglo XX: Balance y Perspectivas. Valencia: Fundación Cañada-Blanch, pp. 237-245. 
